\title{
Perspectives
}

\section{Psychological aspects of pre-symptomatic testing for Machado-Joseph disease and familial amyloid polyneuropathy type I}

Rolim L, Leite Â, Lêdo S, Paneque M, Sequeiros J, Fleming M. Psychological aspects of pre-symptomatic testing for Machado-Joseph disease and familial amyloid polyneuropathy type I.

Clin Genet 2006: 69: 297-305. (C) Blackwell Munksgaard, 2006

Machado-Joseph disease [MJD, also spinocerebellar ataxia type 3 (SCA3)] and familial amyloid polyneuropathy type I (FAP-I or ATTR V30M) are neurodegenerative disorders, inherited in an autosomal dominant fashion, which have a high prevalence in Portugal, probably due to a founder effect. MJD and FAP-I are late-onset diseases, with symptoms emerging usually during adulthood. CGPP, which is the national reference centre for these disorders, has a genetic lab that offers diagnostic, pre-symptomatic and prenatal testing and an outpatient clinic to counsel and follow relatives at risk for hereditary ataxias, FAPI and Huntington disease (HD). The present work is a review of our 10year experience with psychological counselling of individuals at risk for MJD and FAP-I. Persons at risk for FAP-I may show a better response to pre-symptomatic testing than those who are at risk for MJD and HD because of the availability of liver transplantation, which may improve their health and life expectancy. Psychological well-being and specific distress of MJD and FAP-I test applicants, before undergoing genetic testing (baseline level) and 3 to 6 months after disclosure of test results, have shown a low level of change, both in identified carriers and noncarriers. A major goal of psychological characterization of at-risk individuals for MJD and FAP-I is to determine the factors that influence the uptake of genetic testing.

\author{
L Rolim ${ }^{\mathrm{a}}$, Â Leite ${ }^{\mathrm{a}}$, S Lêdo ${ }^{\mathrm{a}}$, \\ $M_{\text {Paneque }}{ }^{\mathrm{c}}$, J Sequeiros ${ }^{\mathrm{a}, \mathrm{b}}$ and \\ M Fleming ${ }^{a, b}$ \\ ${ }^{a}$ Centro de Genética Preditiva e \\ Preventiva (CGPP), Institute for Molecular \\ and Cell Biology (IBMC), ' ICBAS, \\ University of Porto, Portugal, and \\ 'Department of Predictive Genetics, \\ CIRAH, Holguín, Cuba
}

\begin{abstract}
Key words: familial amyloidosis - genetic counselling - genetic testing - hereditary ataxias - psychosocial genetics

Corresponding author: L. Rolim, CGPPIBMC, University of Porto, Campo Alegre, 823, 4150-180 Porto, Portugal.

Tel.: +3512260749 94;

fax: +351226002923;

e-mail: Irolim@ufp.pt
\end{abstract}

Received 16 November 2005, revised and accepted for publication 22 February 2006
The genetic revolution of the last decades provided new tools for medical practice, such as DNA-predictive testing for a broad range of diseases. Pre-symptomatic DNA testing is currently available for many late-onset neurogenetic disorders; Huntington disease (HD) was the first to use this new paradigm and has served as a model for other neurodegenerative disorders (1-3).

Machado-Joseph disease (MJD), also known as spinocerebellar ataxia type 3 (SCA3), and familial amyloid polyneuropathy type I (FAP-I or ATTR V30M), a peripheral neuropathy, are two neurological, dominant disorders with late onset, which are more frequent in Portugal than in most other countries (4-6). Both are suitable for diagnostic, pre-symptomatic, prenatal testing and pre-implantation genetic diagnosis (6-10).
Our research centre has accumulated experience regarding MJD and FAP-I (6-9, 11-15). As in HD, asymptomatic individuals at risk for both those late-onset diseases now can learn, through genetic testing, their future risk of developing the illness present in their families. Informed people are free to decide whether or not to take the test. This decision generates emotional distress and involves major personal issues (16-18), with the potential for short- to long-term psychological consequences for the individual and his/her family $(19,20)$.

\section{Clinical features of MJD}

MJD is a SCA, with an autosomal dominant inheritance, which impairs postural balance and 


\section{Rolim et al.}

coordination of all body movements, including gait, speech and fine movements of the hands $(21,22)$. Symptoms start late, at an average age of 40.2 years (43.7 years for women and 37.3 years for men). MJD also presents with ocular anomalies (limitation of eye movements and diplopia), dystonia, peripheral amyotrophies and decrease in vibration sense. There is neither mental deterioration nor loss of sphincter control. No treatment is currently available to prevent or delay the appearance of the disease. MJD was firstly described in the USA by Nakano and colleagues (23), where it affected predominantly people with ancestry from the Atlantic islands of the Azores who are living mainly in Portugal, USA, Canada and Brazil $(22,24,25)$. MJD is due to the expansion of a CAG repeat (as in HD) within the coding region of $M J D / A T X N 3$ gene on chromosome $14 \mathrm{q} 32.1(26,27)$. It is the most prevalent SCA worldwide (28). The highest incidence (about $1: 4000$ ) is among Azoreans, in Portugal, the USA, Canada and Brazil; in Flores (a Portuguese island of the Azores), MJD reaches the highest prevalence $(1: 140)$ reported worldwide (22).

\section{Clinical features of FAP-I}

FAP-I (ATTR V30M) is also a severe autosomal dominant disorder that was first described by the Portuguese neurologist Corino Andrade $(4,29)$. The original mutation may have occurred or been introduced, many centuries ago, in an individual from Póvoa, a fishermen settlement on the northern coast of Portugal (30). FAP-I has propagated along the Portuguese coast and throughout the world, possibly during the pioneering sea travels of Portuguese sailors in the XV and XVI centuries (30). FAP is present also in a number of other countries, such as Japan (the second largest focus), Brazil, Sweden and some Mediterranean countries $(30,31)$. The north of Portugal has a high prevalence rate: in 1991, this was estimated as $105: 10^{5}$ in Póvoa de Varzim and Vila do Conde (32). In Portugal, over 1700 patients, from 500 unrelated kindreds, have been registered at the Centro de Estudos de Paramiloidose, representing the largest concentration of FAP in the world (33).

FAP-I results from a single mutation in the TTR gene, located on chromosome 18q11.212.1 , leading to a sensory motor neuropathy with autonomic dysfunction. The mutation leads to the production of an abnormal transthyretin (TTR V30M), which is degraded, bound and precipitated in tissues as amyloid fibrils (34). The mutant TTR was then identified (34), which allowed for the identification of FAPI patients all over the world (35). The mean age of onset of FAP-I is 33.5 years, but it can start between 17 and 78 years of age (8). FAP-I duration is, on average, 11 years. Liver transplantation is the only medical procedure that seems to slow down the progress of symptoms of FAP-I $(36,37)$.

\section{DNA pre-symptomatic testing}

The identification of the relevant genes for MJD and FAP-I allowed the molecular diagnosis, as well as pre-symptomatic testing of at-risk persons.

It is pertinent to recall some early lessons learned from HD pre-symptomatic testing. It is clear that genetic testing should be offered as part of a protocol by a multidisciplinary team, which should include a clinical geneticist, a clinical psychologist, a neurologist and a social worker. At least two pre-test counselling sessions and several follow-up sessions are offered to at-risk individuals to meet their information and emotional needs $(2,38-40)$, which facilitate decision-making and aim to anticipate and prevent adverse responses to genetic testing (41). This approach has been a widely accepted model for other lateonset neurodegenerative diseases, such as MJD and FAP-I $(7,8,17-19,42-44)$.

In Portugal, genetic counselling and pre-symptomatic testing is being offered, at our center, to all adults at risk for MJD since 1995 (7, 45). A major aim of this program is to help those who come to us to be informed about their genotype: we provide them medical, psychological and social support, to facilitate informed decisions and coping in a healthy manner with the results disclosed after pre-symptomatic testing.

In FAP-I, detection of the abnormal $T T R$ has been made, since 1984, in individuals at risk for this disease (34). Since 1999, genetic counselling and psychosocial support have been provided also at our centre for all individuals who search pre-symptomatic testing, taking advantage of the same protocol as for HD and MJD.

\section{Genetic risk}

The threat posed by a hereditary disease causes significant emotional burden on individuals at risk, as well as on their families (46). Although research in this area is still scarce, several authors have studied the psychological dynamics and 
life-long endeavour of living with the risk for a serious genetic disease. The risk status, in particular for late-onset diseases such as HD, MJD and FAP-I, represents a chronic stress because of the feeling of uncertainty and the anxiety experienced (47).

Wexler (48) illuminated the psychological contour of this peculiar state with the metaphor of the ticking bomb, to illustrate the expectant anxiety with which at-risk individuals keep awaiting the first symptoms of the disease. Boutte (49) stated that the experience of being at risk for MJD and the state of living constantly in that tenuous limbo between being or not being a carrier may be experienced as a second family disease.

The hereditary character of MJD and FAP-I, and the inherent risk of transmission to offspring, influences the organization of the family, its beliefs and its identity. Family experiences of genetic risk, and the particular life events that are related to the disease, may develop into distinctive life expectations in each of its members, as well as in the family as a system: family members' timetables become shaped by the timetable of the illness (50).

\section{Genetic counselling}

In pre-symptomatic genetic testing programs, genetic counselling starts from the moment when individuals are informed about their state of risk and the availability of genetic testing, for early definition of their carrier or non-carrier status, and offer of prenatal diagnosis (51).

The potential advantages for individuals at risk who submit themselves to genetic counselling and testing programs are emotional relief, amelioration of anxiety and guilt feelings, discussion and analysis of the most favourable behaviours, reproductive choices and coping styles. In the specific case of pre-symptomatic testing, genetic counselling is related to decision-making processes on whether to determine or not the risk of later suffering from the disease and the risk of transmitting it to their offspring. One of the advantages of knowing their carrier status is the chance to better plan the future so that the most appropriate life conditions may be planned, both for the individuals and their offspring (52).

The potential effects of genetic counselling on the decision to be tested or not, and on understanding information about costs and benefits of doing so, have been explored by several studies, which we describe below.

\section{Relevance of genetic counselling protocols}

Although this overview is devoted to MJD and FAP-I, it is pertinent to recall briefly some relevant information obtained from individuals at risk for HD, which has been serving as a frame of reference for other late-onset genetic conditions. For instance, in a survey carried out among six-hundred families, when HD presymptomatic testing was still performed by linkage analysis and beginning to be offered, the authors (53) concluded that at-risk individuals were aware of the advantages of genetic counselling to facilitate the acquisition and comprehension of the predictive testing results; and, unexpectedly, this sort of information has not led to significant clinical anxiety levels. Studies of the attitudes of 69 individuals at risk for HD estimated that at least $2-6 \%$ may have severe psychiatric or suicidal responses to a carrier result (54). A study of the predictive testing program in Canada revealed that $96 \%$ of the participants expressed satisfaction with it (55). The fact that individuals and their families had suitable counselling and were given the opportunity to discuss and consider future implications of the test results was considered of key importance (55).

In general, there are infrequent adverse outcomes in HD pre-symptomatic testing when careful counselling protocols were followed (56). However, the impact of being diagnosed as a carrier of the HD mutation is significant (40, 57), but this distress associated with testing might be reduced by careful counselling and support before and after testing (58).

All prior data underscore the need for careful preand post-test counselling and for the professional and community resources required to deal with the psychological burden of pre-symptomatic testing on both testees and their relatives.

Regarding FAP-I, Zagalo-Cardoso (59) studied the attitudes of at-risk individuals facing predictive testing and concluded that the best predictors for a good outcome were (i) having previous knowledge about the disease and the testing process, (ii) an accurate perception of the disease burden, (iii) the genetic results received from the testing and (iv) the educational level of the individual having the lowest predictive value. Individuals informed that they were carriers $(n=47)$ had less-favourable outcomes than non-carriers $(n=29)$. But, this was at a time when proper genetic counselling protocols, with multiple sessions and psychosocial evaluation and follow-up, were not yet available for these patients. 


\section{Rolim et al.}

Our experience with MJD and FAP-I suggests that it is useful to distinguish three occasions for genetic counselling: (i) before testing is performed, when counselling is useful to help the decision-making process, (ii) while testees are awaiting for test results, when counselling helps dealing with stress and anxiety of the anticipated news and (iii) after disclosure of their true genetic status, when counselling is of particular importance to help people deal with the impact of the results. Post-test sessions should also be offered to non-carriers, because these individuals also suffer psychological distress, namely feelings of guilt or shame in relation to close relatives that are carriers or already affected $(17,18,60,61)$.

Influence of genetic counselling on marriage and pregnancy decision-making

A total of $61 \%$ of individuals at risk for MJD, living in the Azores Islands, Portugal, reported that carrying the mutation would lead them to the decision to not have children (62). The influence of the risk status was also reflected in these different attitudes of at-risk individuals and by the group of affected people, who needed to consider (i) whether to undertake prenatal diagnosis and (ii) in case the MJD mutation was detected, to decide whether to interrupt the pregnancy. Acceptance of prenatal diagnosis and termination of pregnancy in the presence of the mutation in the foetus was low.

In HD, among 390 candidates in pre-symptomatic testing, only $43 \%$ stated that they would make use of prenatal diagnosis, and only $17 \%$ would interrupt pregnancy in the case of a carrier test result (63).

With regard to FAP-I, attitudes towards procreation, among 70 individuals at risk, depended mostly on educational level and their knowledge about the disease and pre-symptomatic diagnosis: a higher degree on any of these was associated with a worse attitude towards procreation (59). In fact, a stepwise multiple regression analysis showed that these variables accounted for $23 \%$ of the total variation in attitudes towards procreation. This study also indicated that there were no differences between FAP-I carriers and non-carriers, in regard to attitudes towards marriage and procreation.

\section{Summary of genetic counselling studies}

Appropriate implementation of pre-symptomatic and prenatal testing calls for genetic counselling protocols: (i) to guide the decision-making process before testing; (ii) while subjects are awaiting the result and (iii) after results are disclosed.
Post-test sessions should be offered also to those who receive favourable results, as these people may also suffer psychological distress.

The importance of genetic counselling and regular psychological support is well known in diminishing the emotional impact of the test results (56), although research to date has been scarce in longitudinal approaches, which might identify factors that influence adaptation to the test results. In a prospective study of 135 participants in the Canadian program for HD testing, there was a psychological evaluation of the counselees, at intervals of 7-10 days, 6 months and 12 months after receiving their test results (64). Receiving the results of pre-symptomatic testing, even if it indicated an increased risk, could reduce uncertainty and provide an opportunity for appropriate life planning. Therefore, individuals who undergo genetic testing may derive psychological benefits from it.

Huggins and colleagues (65) studied individuals who had received, 2 years before, the result of a low risk for HD. The authors found that $10 \%$ had difficulties in coping with their status. These were the persons who had already made irreversible life decisions, based on the belief that they would develop HD, or those who had unrealistic expectations of the positive effects that would come from a diagnosis of low risk for this disease.

According to a worldwide survey on catastrophic events, organized by the Vancouver group, involving 4527 test participants (66), suicide attempts after HD pre-symptomatic testing were very rare. Another study by Almqvist and colleagues (67) assessed prospectively (over 5 years) the psychological consequences of predictive testing in individuals at risk for HD. A significant reduction in psychological distress was observed throughout 2 years and at 5 years; however, $6.9 \%$ (14 of 202) of the participants experienced a clinically significant adverse event during the first 2 years after undergoing predictive testing. These occurred more frequently in the group with increased risk for HD and mostly within 12 months after receiving the genetic results.

A healthy adaptation to genetic diagnosis has been attributed mainly to appropriate genetic counselling and psychological support within presymptomatic testing programs (61).

\section{Pre-symptomatic testing}

Decision-making

A number of authors (68-72) have studied adherence to pre-symptomatic testing in MJD and explored predictors of genetic testing uptake. 
From the counselees' point of view, benefits of having pre-symptomatic testing for MJD included a reduction in the level of uncertainty and the chance to plan their future, with regard to procreation and to the disease itself (69). Other benefits referred were the possibility of informing the offspring about the risk of developing the disease or even the chance of beginning a medical treatment (not yet available), to prevent its development and/or delay its course $(68,70,73)$. The arguments mentioned by at-risk individuals against taking predictive testing for MJD were the anticipation of negative consequences from a carrier result, namely the emotional consequences on the family and peer groups, as well as difficulties in coping with the potentially tragic future of this debilitating disease.

Regarding predictive testing for FAP-I, several problems were raised by at-risk individuals (8). One of these was the perceived disadvantage of exchanging a $50 \%$ chance of being a carrier for the known certainty offered by the test, if the results were unfavourable. Some felt that this might be intolerable for them and would prefer not to bear any children than to live long years with the prospect that they will certainly suffer from FAP-I in the future. What may be considered as advantageous and justifiable reasons from the medical and public view point (e.g. planning for the future, helping in the choice of a profession, family planning, improving quality of life and contributing to health) may not be recognized as such by the individual (18). Hence, rejection of predictive testing may reflect the perception that genetic knowledge will inevitably have damaging consequences. Of a group of 126 at-risk individuals that were tested for FAP-I in the early years (8) - when no proper pre- and post-test counselling was provided, $58 \%$ stated they took the test because of medical advice, rather than this being a free decision; and, among these, 19\% never came back to ask for the result.

In FAP-I, in contrast with MJD, there is nowadays one feature that significantly alters the psychological burden imposed by the disease, and that may increase uptake of at-risk individuals to pre-symptomatic testing: FAP-I patients are now offered liver transplantation, which may delay the progression of the disease (37). Patients and their families now see FAP-I as being less threatening than other neurodegnerative diseases, such as MJD and HD (36). This is not surprising if one considers that research in other areas has shown that the availability of therapy or preventive measures for a serious disease may increase acceptance of genetic testing
(74). For example, in inherited breast cancer, adherence to testing can reach $89 \%$ (75); on the contrary, whenever these measures are rare or inexistent, the uptake rate is greatly reduced (58).

Preparing in advance for liver transplantation is often cited by the individual at risk for FAP-I as one of the main reasons for taking the presymptomatic test. In fact, the informed at-risk individuals know that, if they are V30M mutation carriers, they will have the chance to register in a waiting list for a liver transplantation once the onset of FAP-I is diagnosed. Because of the availability of this therapy, predictive testing for FAP-I might be perceived as very positive for the tested individual (36). This does not mean, however, that psychological support to FAP-I at-risk individuals, who ask to take the test, should be neglected. Liver transplant is not a trivial procedure and is certainly not the 'cure' for this disease. Thus, support should be pursued, whether or not transplantation takes place, and should continue before and after surgery.

\section{Psychological effects}

Research on the psychological effects of presymptomatic testing is very important, as access to test by at-risk individuals is becoming a reality for many diseases.

The diagnosis of a serious disease such as FAPI is experienced, by gene carriers and patients, as a significant loss. Interestingly, we have found the following psychological characteristics in these patients: (i) their most-frequent complaints are anxiety and/or sadness and discouragement; (ii) they present with high levels of difficulty in communicating their emotions; (iii) they use denial as their main defence mechanism to deal with the pain associated with the knowledge of having the disease and as a consequence (iv) most of them fail to ask for psychological help. FAP-I patients also have an internal experience of the disease that is built on their knowledge from previous generations, i.e. they often see themselves as a mirror of their affected parent (76).

Psychological well-being in persons at risk for HD, MJD and FAP-I coming for pre-symptomatic testing, evaluated by the Psychological General Well Being (PGWB) Schedule, was compared with that in the general population (71). Surprisingly, the individuals at risk presented with less anxiety and higher well-being indicators than the control group. The authors suggested that this could be explained by the fact that at-risk individuals that came to the first session of the protocol were psychologically 


\section{Rolim et al.}

more motivated and resilient, which might be due to their own self-selected (persons less motivated and prepared would exclude themselves from taking the test).

At our research centre, a recent study on presymptomatic testing for FAP-I (73) investigated the psychological effects of receiving a carrier result in 70 at-risk individuals (44 females and 26 males; mean age 24.3 years). Depression, measured by the Beck Depression Inventory (77), and hopelessness, evaluated by the Beck Hopelessness Scale (78), were used as indicators of their psychological mood on three occasions: (i) before testing, (ii) 3 weeks and (iii) 6 months after testing. The scores for depression and hopelessness did not reach pathological levels, at any moment, for the vast majority of subjects. Nevertheless, mean depression scores were higher before testing and lowered three weeks after the carrier result was disclosed; only 12 individuals $(17 \%)$ presented scores $\geq 9$, indicating moderate depression. A $t$-test showed, however, that the differences between those two timings were not statistically significant $(\mathrm{p}=0.293)$. Six months after receiving the results, the majority $(n=32$, $86.5 \%$ ) of the subjects that were informed that they were carriers of the mutation were optimistic about their future. These results suggested that, on average, receiving a carrier result for FAP-I seemed not to have a negative psychological impact or to change the individuals hope for their future.

In Japan, the psychological consequences of genetic testing have been studied in two SCAs (79): SCA1 and MJD (SCA3). Anxiety and social desirability were assessed and analysed both in patients $(n=37)$ and in at-risk family members $(n=25)$. The SCA patients were found to have higher baseline scores for anxiety than their asymptomatic family members. Genetic testing did not significantly increase the scores for all patients or their asymptomatic family members, who were tested, whereas anxiety was greatly reduced in those who had received non-carrier results.

The impact of pre-symptomatic testing for MJD in 19 individuals at risk, in the Azores, has also been studied (72). Depression and anxiety were evaluated before testing, 3 weeks and 9 months after disclosure of the test result. The majority of subjects did not reach pathological levels of depression $(92.3 \% ; 12$ of 13$)$ and anxiety $(85.7 \% ; 12$ of 14$)$, and knowledge of the results proved not to have a negative long-term psychological impact, highlighting their capacity for adaptation to a new and definitive genetic status.
At our research centre, only a small number of couples (83, so far, including the first two cases of prenatal testing for MJD) $(11,80)$ have come for prenatal diagnosis of HD, MJD or FAP-I. A few others have undergone or are currently undergoing pre-implantation genetic diagnosis for any of these diseases.

\section{Conclusions}

Clearly, our national program for presymptomatic testing and genetic counselling of late-onset neurological disorders, which has now been running for one decade (10 years for MJD, and 7 and 6 years for HD and FAP-I, respectively), will require re-evaluation and continuous improvement in its psychosocial assessment and intervention protocols. This is particularly important in Portugal because of a regional high prevalence for FAP-I and for MJD, which represent serious public health problems in some areas of the mainland and the Azores. Our experience shows that genetic testing for late-onset neurological diseases calls for special attention from psychologists and other health professionals in the application of genetic counselling and psychosocial support protocols.

We believe that psychological intervention in genetic testing programs for MJD and FAP-I must include, in the future, the following goals: (i) understanding the reasons why at-risk individuals may decide to have (or not to have) the test, (ii) determining their expectations towards pre-symptomatic testing and its results, (iii) to help individuals anticipating and considering personal advantages and disadvantages of having the test and (iv) to help them integrating, both cognitively and emotionally, the results of the test.

We are further developing a number of research areas (i) to identify the possible psychosocial predictors of uptake of testing, (ii) to predict the risk of psychological disturbances and the social impact after changing genetic status, (iii) to improve psychological evaluation protocols and tools in the pretest phase, to increase their sensitivity in identifying the subjects psychologically more vulnerable to adverse reactions and (iv) to develop efficient psychological intervention strategies, aimed at preventing emotional risk and helping subjects to deal with the burden caused both by the decision-making process and the genetic result itself.

Till now, investigations have been limited to individuals who participate in genetic counselling 
programs. In particular, those who do not participate should also be a subject of research. Also, longer term follow-up of individuals who underwent genetic testing for MJD and FAP-I is needed to assess the later impact of testing and also to determine the best predictors of psychological response to genetic results.

\section{Acknowledgements}

This work has been funded by the Portuguese Science and Technology Foundation (FCT) through fellowships (to L. Rolim, A. Leite and M. Paneque). CGPP, IBMC (JS) is a partner of EuroGentest - Genetic Testing in Europe (http:// www.eurogentest.org) and of PHGEN - Public Health Genomics Network (http://www.phgen.nrw.de).

\section{References}

1. Gusella J, Wexler N, Conneally $\mathrm{M}$ et al. A polymorphic DNA marker genetically linked to Huntington's disease. Nature 1983: 306: 234-238.

2. Benjamin C, Adam S, Wiggins S et al. Proceed with care: direct presymptomatic testing for Huntington disease. Am J Hum Genet 1994: 55: 607-617.

3. Witjes-Ané MW, Zwinderman A, Tibben A et al. Behavioral complaints in participants who underwent presymptomatic testing for Huntington's disease. J Med Genet 2002: 39: 857-862.

4. Andrade C. A peculiar form of peripheral neuropathy: familial atypical generalized amyloidosis with special involvement of the peripheral nerves. Brain 1952: 75: 408-427.

5. Sequeiros J, Saraiva MJ. Onset in the seventh decade and lack of symptoms in heterozygotes for the TTRMet30 mutation in hereditary amyloid neuropathy - type I (Portuguese, Andrade). Am J Med Genet 1987: 27: 345-357.

6. Maciel P, Gaspar C, DeStefano AL et al. Correlation between $\mathrm{CAG}$ repeat length and clinical features in Machado-Joseph disease. Am J Hum Genet 1995: 57: 54-61.

7. Sequeiros J. Protocolo Geral do Programa Nacional de Teste Preditivo e Aconselhamento Genético na Doença de Machado-Joseph [General Protocol for Predictive Testing and Genetic Counselling for Machado-Joseph Disease]. In: Sequeiros, J, ed. O Teste Preditivo Da Doença de Machado-Joseph [Predictive Testing for Machado-Joseph Disease]. Porto: Unigene, IBMC, 1996: 123-149.

8. Coelho TA. Experiência do Aconselhamento Genético na Polineuropatia Amiloidótica Familiar [Experience of Genetic Counselling in Familial Amyloid Neuropathy]. In: Sequeiros, J, ed. O Teste Preditivo Da Doença de Machado-Joseph [Predictive Testing for Machado-Joseph Disease]. Porto: Unigene, IBMC, 1996: 71-77.

9. Maciel P, Costa MC, Ferro A et al. Improvement in the molecular diagnosis of Machado-Joseph disease. Arch Neurol 2001: 58 (11): 1821-1827.

10. Carvalho F, Sousa M, Fernandes S et al. Preimplantation genetic diagnosis for familial amyloid polyneuropathy (FAP). Prenat Diagn 2001: 21 (12): 1093-1099.

11. Pinto-Basto J, Coelho T, Leal Loureiro J et al. Prenatal diagnosis (PND) in late-onset neurological disorders in
Psychological aspects of pre-symptomatic testing

Portugal: 83 requests, since 1996. Eur J Hum Genet (in press).

12. Costa MC, Gomes-da-Silva J, Miranda CJ et al. Genomic structure, promoter activity, and developmental expression of the mouse homologue of the Machado-Joseph disease (MJD) gene. Genomics 2004: 84 (2): 361-373.

13. Jardim L, Silveira I, Pereira ML et al. Searching for modulating effects of SCA2, SCA6 and DRPLA CAG tracts on the Machado-Joseph disease (SCA3) phenotype. Acta Neurol Scand 2003: 107 (3): 211-214.

14. Monte TL, Rieder CR, Tort AB et al. Use of fluoxetine for treatment of Machado-Joseph disease: an open-label study. Acta Neurol Scand 2003: 107 (3): 207-210.

15. Lobato L, Beirão I, Silva $M$ et al. End-stage renal disease and dialysis in hereditary amyloidosis TTR V30M: presentation, survival and prognostic factors. Amyloid 2004: 11 (1): 27-37.

16. Motulsky AG. Invited editorial: predictive genetic testing. Am J Hum Genet 1994: 55: 603-605.

17. Lopes A, Fleming M. Aspectos psicológicos da polineuropatia amiloidótica familiar: a trama subterrânea intergeracional [Psychological aspects of familial amyloid neuropathy: the subterranean inter-generational crossthreads]. Brotéria Genética 1998: XIX (XCIV): 183-192.

18. Fleming M, Lopes A. Saber ou não saber: dinâmica e impasses psicológicos na doença genética [To know or not to know: the dynamics and psychological impasse in genetic disease]. Revista Portuguesa Psicossomática 2000: 2 (1): 33-40.

19. Evers-Kiebooms G, Welkenhuysen M, Claes E et al. The psychological complexity of presymptomatic testing for late onset neurogenetic diseases and hereditary cancers: implications for multidisciplinary counseling and for genetic education. Soc Sci Med 2000: 51: 831-841.

20. Paúl C, Martin I, Silva MR et al. Living with MachadoJoseph disease in a small rural community of the Tagus valley. Community Genet 1999: 2 (4): 190-195.

21. Coutinho P, Andrade C. Autosomal dominant system degeneration in Portuguese families of the Azores Islands. Neurology 1978: 28: 703-709.

22. Sequeiros J, Coutinho P. Epidemiology and clinical aspects of Machado-Joseph disease. In: Harding AE, Deufel T, Chamberlain S, eds. Hereditary ataxias. advances in neurology. New York: Raven Press, 1993: 139-153.

23. Nakano K, Dawson D, Spence A. Machado disease: a hereditary ataxia in Portuguese emigrants to Massachusetts. Neurology 1972: 22: 49-55.

24. Lima M, Kay T, Vasconcelos JA et al. Disease knowledge and attitudes toward presymptomatic testing and prenatal diagnosis in families with Machado-Joseph disease from the Azores Islands (Portugal). Community Genet 2001: 4 (1): 36-42.

25. Jardim LB, Silveira I, Pereira ML et al. A survey of spinocerebellar ataxia in South Brazil - 66 new cases with Machado-Joseph disease, SCA7, SCA8, or unidentified disease-causing mutations. J Neurol 2001: 248 (10): $870-876$

26. Kawaguchi Y, Okamoto T, Taniwaki M et al. CAG expansions in a novel gene for Machado-Joseph disease at chromosome 14q32.1. Nat Genet 1994: 8: 221-228.

27. Sequeiros J, Silveira I, Maciel P et al. Genetic linkage of Machado-Joseph disease to chromosome 14q SRTPs in 16 Portuguese-Azorean kindreds. Genomics 1994: 21: 645-648.

28. Gaspar C, Lopes-Cendes I, Hayes S. Ancestral origins of the Machado-Joseph disease mutation: a worldwide haplotype study. Am J Hum Genet 2001: 68 (2): 523-528. 
29. Sequeiros J. In Memoriam. Clin Genet 2006: 69 (2): 194-196.

30. Costa PP. History and geography of familial amyloidotic polyneuropathy, Portuguese type. In: Sales Luís ML, Bigotte de Almeida L, Pinho e Costa, eds. Symposium on Peripheral Neuropathies and Satellite Symposium on Familial Amyloid Polyneuropathy. Lisbon, 1986, 201-206.

31. Drugge U. Familial amyloidosis with polyneuropathy in Sweden: some notes of its historical background. In: Costa PP, Falcão de Freitas A, Saraiva MJ, eds. Familial Amyloid Polyneuropathy and Other Transthyretin Related Disorders. Umeå: Medical Archives; Porto: Centro de Estudos de Paramiloidose, 1990.

32. Sousa A, Coelho T, Barros J et al. Genetic epidemiology of familial amyloid polyneuropathy (FAP) type I in Póvoa de Varzim and Vila do Conde (North of Portugal). Am J Med Genet 1995: 60: 512-521.

33. Lobato L. Portuguese-type amyloidosis (transthyretin amyloidosis, ATTR V3OM). J Nephrol 2003: 16: 438-442.

34. Saraiva MJ, Birken S, Costa PP et al. Amyloid fibril protein in familial amyloidotic polyneuropathy, Portuguese type. Definition of molecular abnormality in transthyretin (prealbumin). J Clin Invest 1984: 74 (1): 104-119.

35. Saraiva MJ. Sporadic cases of hereditary systemic amyloidosis. N Engl J Med 2002: 346: 1786-1791.

36. Sales-Luís ML, Conceição I, Carvalho M. Clinical and therapeutic implications of presymptomatic gene testing for familial amyloid polyneuropathy (FAP-I). Amyloid J Protein Folding Disorders 2003: 10 (Suppl. I): 26-31.

37. Herlenius G, Wilczek HE, Larsson M. Familial Amyloid Polyneuropathy World Transplant Registry. Ten years of international experience with liver transplantation for familial amyloid polyneuropathy: results from the familial amyloid polyneuropathy world transplant registry. Transplantation 2004: 77 (1): 64-71.

38. European Community Huntington's Disease Collaborative Study Group. Ethical and social issues in presymptomatic testing for Huntington's disease: a European community collaborative study. J Med Genet 1993: 30: 1028-1035.

39. Huntington's Disease Collaborative Research Group. A novel gene containing a trinucleotide repeat that is expanded and unstable in Huntington's disease. Am J Med Genet 1993: 72: 971-983.

40. Tibben A, Vegter-van der Vlis M, Skraastad M et al. DNAtesting for Huntington's disease in the Netherlands: a retrospective study on psychosocial effects. Am J Med Genet A 1992: 44: 94-99.

41. Bloch M, Fahy M, Fox S et al. Presymptomatic testing for Huntington disease: II. Demographic characteristics, lifestyle patterns, attitudes, and psychosocial assessments of the first fifty-one test candidates. Am J Med Genet A 1989: 32: 217-224.

42. Dudok de Wit A, Tibben A, Duivenvoorden H. Rotterdam/ Leiden Genetics Workgroup. Distress in individuals facing presymptomatic DNA testing for autosomal dominant lateonset disorders: comparing questionnaire results with indepth interviews. Am J Med Genet A 1998: 75: 62-74.

43. Taylor S. Presymptomatic genetic testing: new conundrums and moral imperatives. Paper presented at Towards Humane Technologies: Biotechnology, New Media and Citizenship. An International Conference Exploring the Social, Moral and Political Implications of Biotechnology Research and Commercialization. The University of Queensland, November 14, 2002, Ipswich, Queensland. Accessed from http://www.uq.edu.au/gsm/Confpapers/ Taylor.doc.
44. Tibben A. Genomics and dissemination of genetic information to individuals at-risk: the need for a proactive approach? Essay presented at Leids Universitair Medish Centrum, November 14, 2002, Klinische Genetica. Accessed from http://www.nwo.nl/NWOHome.nsf/pages/ NWOP_5DPCTM \%24file/Thema3.Tibben.

45. Sequeiros J. Aconselhamento Genético e Teste Preditivo na Doença de Machado-Joseph [Genetic Counselling and Predictive Testing for Machado Joseph's disease]. In: Sequeiros J, ed. O Teste Preditivo Da Doença de Machado-Joseph [Predictive Testing for Machado-Joseph Disease]. Porto: UnIGENe, IBMC, 1996: 97-112.

46. Sobel S, Cowan D. Impact of genetic testing for Huntington disease on the family system. Am J Med Genet 2000: 90: 49-59.

47. Bird T. Risks and benefits of DNA testing for neurogenetic disorders. Seminars Neurol 1999: 19 (3): 253-259.

48. Wexler NS. Genetic 'Russian roulette': the experience of being 'at-risk' for Huntington's disease. In: Kessler S, ed. Genetic counseling: psychological dimensions. New York: Academic Press, 1979, 199-220.

49. Boutte M. Waiting for the family legacy: the experience of being at-risk for Machado-Joseph disease. Soc Sci Med 1990: 30 (8): 839-847.

50. Gonzalez S, Steinglass P, Reiss D. Putting the illness in its place. Fam Process 1989: 28: 69-88.

51. Wertz DC, Fletcher JC, Berg K. Review of ethical issues in medical genetics (WHO/HGN/ETH/00.4). Geneva, Switzerland: World Health Organization, 2003.

52. Penchaszadeh V, Puñales-Morejón D. Dimensiones psicosociales de los problemas genéticos [The psychosocial dimensions of genetic problems]. Teaching material. New York: Beth Israel Medical Center, Division of Medical Genetics, 2000.

53. Swavely S, Silverman W, Falek A. Psychological impact of the development of a presymptomatic test for Huntington's disease. Health Psychol 1987: 6 (29): 149-157.

54. Kessler S, Field T, Worth L et al. Attitudes of persons atrisk for Huntington disease toward presymptomatic testing. Am J Med Genet B Neuropsychiatr Genet 1987: 26: 259-270.

55. Copley TT, Wiggins S, Dufrasne $\mathrm{S}$ et al. Are we all of one mind? Clinicians' and patients' opinions regarding the development of a service protocol for predictive testing for Huntington disease. Canadian Collaborative Study for Predictive Testing for Huntington Disease. Am J Med Genet 1995: 58 (1): 59-69.

56. Bundey S. Few psychological consequences of presymptomatic testing for Huntington's disease. Lancet 1997: 349: 4.

57. Evers-Kiebooms G, Nys K, Harper P et al. Presymptomatic DNA-testing for Huntington's disease and reproductive decision-making: a European collaborative study. Eur J Hum Genet 2002: 10 (3): 167-176.

58. Marteau TM, Croyle R. Psychological responses to genetic testing. BMJ 1998: 316: 693-696.

59. Zagalo-Cardoso J. Aconselhamento genético: para uma valorização do paradigma psicológico [Genetic counselling: towards a valorization of the psychological paradigm]. $\mathrm{PhD}$ Dissertation Thesis. Portugal: University Coimbra, 1995.

60. Fleming M. Intervenção psicológica na crise: a experiência com a paramiloidose [Psychological intervention during crisis: the experience with paramyloidosis]. In: Sequeiros, J, ed. O Teste Pré-Sintomático Da Doença de MachadoJoseph [Presymptomatic Testing for Machado-Joseph Disease]. Porto: Unigene, IBMC, 1996: 65-70.

61. Fleming M, Lêdo S, Rocha JC et al. Impacto psicológico do teste pré-sintomático na doença de Machado-Joseph. 
Resultados preliminares [Psychological impact of presymptomatic testing for Machado-Joseph's Disease. Preliminary findings]. Arq Med (Porto) 2004: 18 (1/2): 72-75.

62. Lima M, Kay T, Vasconcelos J et al. Disease knowledge and attitudes toward presymptomatic testing and prenatal diagnosis in families with Machado-Joseph disease from the Azores Islands (Portugal). Community Genet 2001: 4: $36-42$.

63. Adam S, Wiggins S, Whyte $P$ et al. Five year study of prenatal testing for Huntington's disease: demand, attitudes, and psychological assessment. J Med Genet 1993: 30 (7): 549-556.

64. Wiggins S, Whyte P, Huggins $M$ et al. The psychological consequences of presymptomatic testing for Huntington's disease. N Engl J Med 1992: 327 (20): 1401-1405.

65. Huggins M, Bloch M, Wiggins S et al. Presymptomatic testing for Huntington disease in Canada: adverse effects and unexpected results in those receiving a decreased risk. Am J Hum Genet 1992: 42: 508-515.

66. Almqvist E, Bloch M, Brinkman R et al. A worldwide assessment of the frequency of suicide, suicide attempts, or psychiatric hospitalization after presymptomatic testing for Huntington Disease. Am J Hum Genet 1999: 64: 1293-1304.

67. Almqvist EW, Brinkman RR, Wiggins $\mathrm{S}$ et al. Psychological consequences and predictors of adverse events in the first 5 years after predictive testing for Huntington's disease. Clin Genet 2003: 64 (4): 300-309.

68. Paúl MC. Reacções esperadas aos resultados do teste présintomático: a experiência dos programas da doença de Huntington [Expected reactions to the results of presymptomatic testing: the experience of Huntington's disease programs]. In: Sequeiros, J, ed. O Teste Preditivo Da Doença de Machado-Joseph [Predictive Testing for MachadoJoseph Disease]. Porto: Unigene, IBMC, 1996: 79-94.

69. Paúl MC. Genética Psicossocial: o estudo das atitudes face à realização do teste pré-sintomático da doença de Machado-Joseph [Psychosocial genetics: study of attitudes towards presymptomatic testing for Machado-Joseph disease]. Psicologia: Teoria, Invest e Prática [Psychology, Theory, Res Prac] 1997: 2 (2): 241-250.

70. Rolim L. Psicologia clínica na doença de Machado-Joseph: estudo de instrumentos de avaliação, no contexto do teste pré-sintomático [Clinical psychology in Machado-Joseph disease: a study of the instruments for evaluation in the context of presymptomatic testing]. MSc Thesis. Portugal: University Coimbra, 2000

71. Leite A, Sequeiros J, Paúl C. O bem-estar psicológico em indivíduos de risco para doenças neurológicas hereditárias de aparecimento tardio e controlos. [Psychological wellbeing in individuals at-risk for late-onset hereditary neurological diseases and controls]. Psicologia, Saúde Doenças 2002: 3 (2): 113-118

72. Gonzalez C, Lima M, Kay T et al. Short-term psychological impact of predictive testing for Machado-Joseph disease: depression and anxiety levels in individuals at risk from Azores (Portugal). Community Genet 2004: 7: 196-201.

73. Lêdo S. O primeiro dia do resto das suas vidas. alguns aspectos psicológicos da Paramiloidose. [The first day of the rest of their lives: some psychological aspects of Paramyloidosis]. MSc Thesis. Lisbon, Portugal: ISPA, 2002.

74. Evans D, Maher E, Macleod R et al. Uptake of genetic testing for cancer predisposition. J Med Genet 1997: 34: 746-748.

75. Kelly K, Leventhal H, Andrykowski $\mathrm{M}$ et al. The decision to test in women receiving genetic counseling for BRCA1 and BRCA2 mutations. J Genet Couns 2004: 13 (3): 237-257.

76. Lopes A, Fleming M. Doença somática e organização psíquica: reflexões a partir da polineuropatia amiloidótica familiar (P.A.F.) [Somatic disease and psychic organization: reflections on familial amyloid polyneuropathy (FAP-I)]. Revista Portuguesa de Psicanálise 1996: 15: 93-100.

77. Beck AT, Ward $\mathrm{CH}$, Mendelson $\mathrm{M}$ et al. An inventory for measuring depression. Arch Gen Psychiatry 1961: 4: 561-571.

78. Beck AT, Weissman A, Lester D et al. The measurement of pessimism: the hopelessness scale. J Consult Clin Psychol 1974: 42: 861-865.

79. Koji A, Itoyama Y. Psychological consequences of genetic testing for spinocerebellar ataxia in the Japanese. Eur $\mathrm{J}$ Neurol 1997: 4 (6): 593-600.

80. Sequeiros J, Maciel P, Taborda F et al. Prenatal diagnosis of Machado-Joseph disease by direct mutation analysis. Prenat Diagn 1998: 18: 611-617. 